\title{
Kupffer Cell Aggregation and Perivenular Distribution in Steatohepatitis
}

Jay H. Lefkowitch, M.D., Jennifer H. Haythe, M.D., Nicole Regent, M.D.

Departments of Pathology (JHL) and Medicine (JHH), College of Physicians and Surgeons, Columbia

University; and Department of Psychiatry (NR), The New York Hospital-Weill Medical Center,

New York, New York

Cytokine release from inflammatory cells, endotoxin, lipid peroxidation, and generation of reactive oxygen species are among the factors currently thought to be important in the pathogenesis of alcoholic and nonalcoholic steatohepatitis (SH). To more fully evaluate the role of mononuclear inflammatory cells in $\mathrm{SH}, 11$ needle liver biopsies showing SH were selected for immunohistochemical staining to analyze the type and distribution of mononuclear inflammatory cells, including $T$ and $B$ lymphocytes and Kupffer cells (using immunostains for CD3, CD4, CD8; CD20; and CD68, respectively). An additional seven biopsies showing normal or fatty liver were also selected for CD68 immunostaining. Immunohistochemistry showed mild to moderate $(1+$ to $2+)$ numbers of $T$ cells, with equal representation of $\mathrm{CD} 4$ and CD8 cells. T cells were found in portal tracts and in regions of SH. B cells were only rarely present. CD68 staining of simple fatty liver and normal liver showed elongated, spindle-shaped Kupffer cells diffusely distributed along the sinusoids throughout the lobules. In contrast, in cases of $\mathrm{SH}$, there was prominent enlargement and aggregation of Kupffer cells in perivenular regions. Scattered large vacuoles of fat that had appeared to be within hepatocytes on routine stain were found actually to be within Kupffer cells. These results support the concept that hepatic Kupffer cells are a major immune effector cell in the pathogenesis of steatohepatitis. A potential direct Kupffer cell role in hepatic lipid processing is also postulated.

Copyright () 2002 by The United States and Canadian Academy of Pathology, Inc.

VOL. 15, NO. 7, P. 699, 2002 Printed in the U.S.A.

Date of acceptance: April 11, 2002.

Address reprint requests to: Jay H. Lefkowitch, M.D., Department of Pathology, College of Physicians and Surgeons, 630 West 168th Street, New York, NY 10032; e-mail: jhl3@columbia.edu; fax: 212-305-5498.

DOI: 10.1097/01.MP.0000019579.30842.96

KEY WORDS: Fatty liver, Kupffer cells, Liver biopsy, Liver pathology, Steatohepatitis.

Mod Pathol 2002;15(7):699-704

Steatohepatitis (SH) has received exceptional attention in clinical and research hepatology during the past decade because of the wide prevalence of alcohol use, obesity, and diabetes $(1,2)$. The pathogenesis of $\mathrm{SH}$ is related to the oxidative stress and lipid peroxidation associated with the fatty liver (3), endotoxemia (4), activation of hepatic stellate cells, and a complex cytokine network in which production of tumor necrosis factor (TNF)- $\alpha$ is prominent (5-7). Although classic morphologic studies of alcoholic steatohepatitis (ASH; 8-10) and, more recently, of nonalcoholic steatohepatitis (NASH; 1113) have demonstrated the prominence of neutrophilic leukōcytes within the centrilobular lesion of steatohepatitis (hepatocyte ballooning, fatty change, Mallory bodies, and pericellular/perisinusoidal fibrosis), current hypotheses concerning the pathogenesis of $\mathrm{SH}$ indicate major roles for lymphocytes and macrophages (Kupffer cells).

-In this study, immunohistochemical stains of 11 needle liver biopsies showing steatohepatitis were used to demonstrate $\mathrm{T}$ cells (including $\mathrm{CD} 4$ and CD8 cells), B cells, and Kupffer cells. The type and distribution of these mononuclear cells were evaluated with regard to current data concerning the pathogenesis of $\mathrm{SH}$.

\section{MATERIALS AND METHODS}

The files of the Division of Surgical Pathology of the Department of Pathology, ColumbiaPresbyterian Medical Center, were searched for liver biopsies with a diagnosis of SH from 1990 to 2001. Eleven cases (needle biopsies) were selected, and the medical records of the respective patients were reviewed for history of alcohol use, obesity, diabetes or other putative etiologic factors. Seven control cases were also selected for CD68 (Kupffer cell) immunohistochemical staining once the CD68 

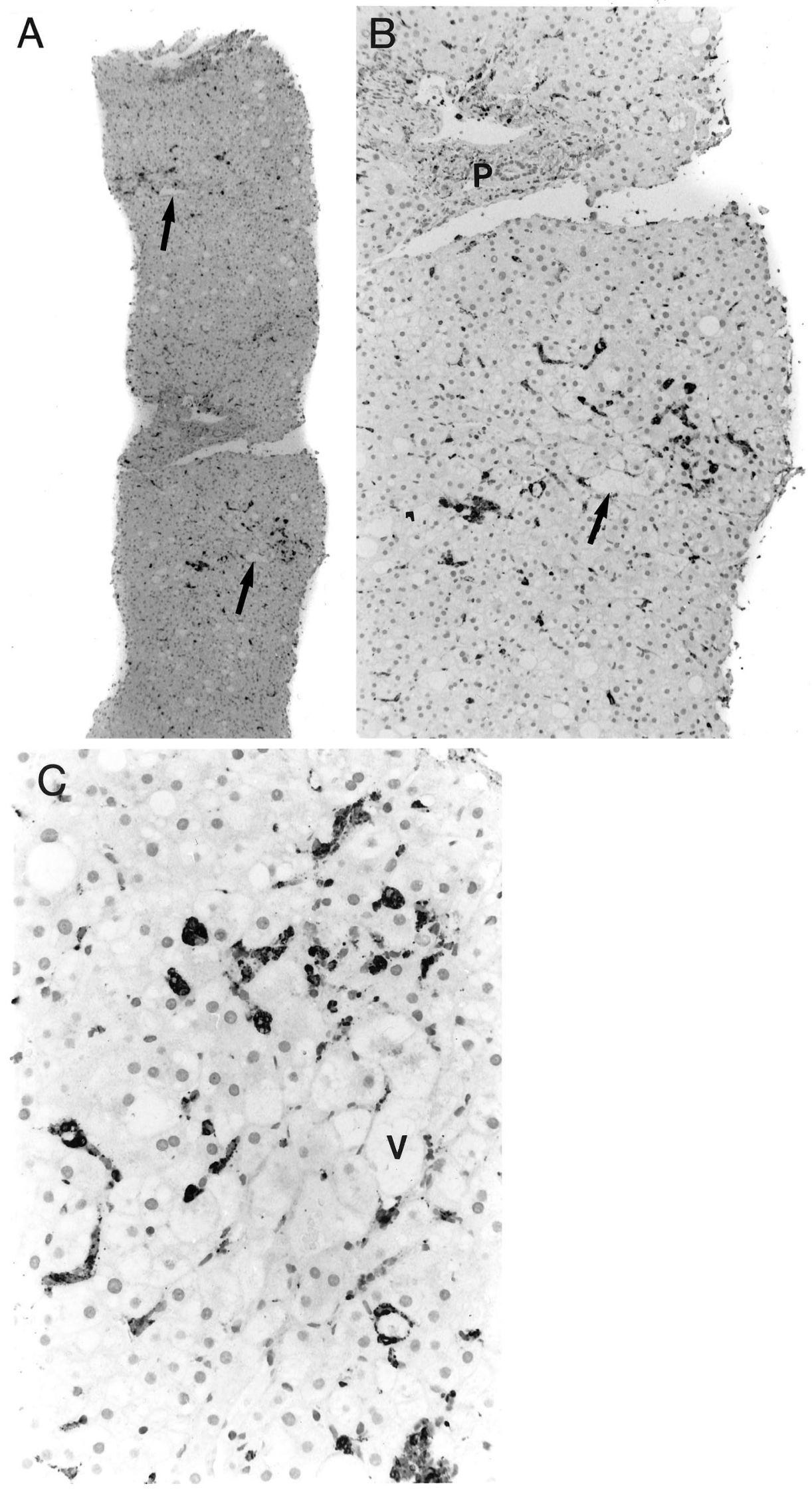

FIGURE 1. CD68 immunostaining of Kupffer cells in a case of mild steatohepatitis. A, low magnification shows prominent aggregated Kupffer cells near the central veins (arrows; magnification, 50×). B, a portion of $\mathbf{A}$ shows a portal tract (P) and aggregated prominent Kupffer cells near the central vein (arrow). Individual elongated Kupffer cells in the midzonal and periportal regions are less conspicuous (magnification, 125×). C, aggregated Kupffer cells with enlarged, rounded cell bodies and intracytoplasmic granules are present near mildly ballooned hepatocytes and the central vein (V; magnification, $325 \times$ ). 


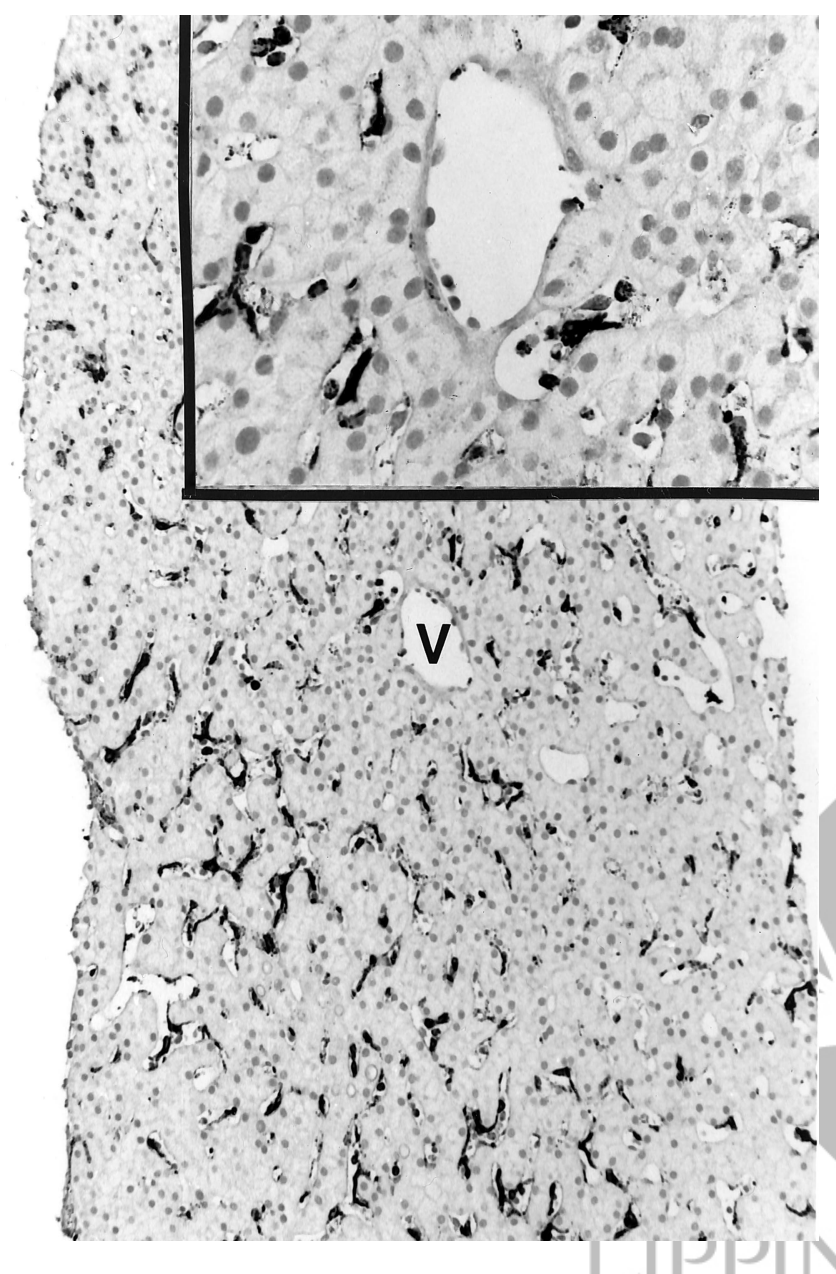

FIGURE 2. CD68 immunostaining of normal control liver shows individual elongated Kupffer cells diffusely within the sinusoids. ( $\mathrm{V}=$ central vein; magnification, $125 \times$.) Inset, individual, elongated, tapering Kupffer cells are present within sinusoids (magnification, 325×).

staining results for $\mathrm{SH}$ cases were apparent. These included three normal liver biopsies, two with mild or moderate fat, and two with marked fat.

Immunohistochemical staining was performed on deparaffinized sections from paraffinembedded, formalin-fixed needle liver biopsy specimens using the DAKO EnVision ${ }^{\mathrm{TM}}+$ System, Peroxidase (3,3'-diaminobenzidine), a two-step immunohistochemical technique using an avidin and biotin-free horseradish peroxidase-labeled polymer conjugated with secondary antibodies to bind to the primary antibody. The primary mouse monoclonal antibodies used included CD3 (T cells), CD8 (T cytotoxic/suppressor cells), CD20 (B cells), and CD68 (Kupffer cells/macrophages) from DAKO (Carpinteria, CA) and CD4 (T helper/inducer cells) from Novocastra, distributed by Vector (Burlingame, CA).

Immunohistochemical staining results were reviewed, and the numbers of respective positively stained immune cells were graded as follows: 0 (none); R (rare cells present); 1+ (few); 2+ (moderate numbers); 3 (many). Notation was made of their specific location, including perivenular (V), within portal tracts (P), within lobular sinusoids (L), and within fibrous septa (SE).

\section{RESULTS}

Immune cells in Steatohepatitis Cases

$T$ and $B$ cells

CD3-positive T cells were found in mild to moderate numbers within portal tracts and fibrous septa and in regions of perivenular steatohepatitis. The $\mathrm{T}$ cells were composed of an equal admixture of CD4- and CD8-positive cells. B cells were only rarely identified at any site.

\section{Kupffer cells}

Aggregates of prominent CD68-positive Kupffer cells were present in perivenular regions of $\mathrm{SH}$, readily seen even at low magnification (Fig. 1A-C). At these sites they were characterized by enlarged and rounded cell bodies containing numerous densely stained intracellular granules (positive lysosomal staining). Elsewhere, along sinusoids in the midzonal and periportal regions, Kupffer cells were nonaggregated, individual cells with elongated tapering cell bodies identical to the appearance of CD68-stained Kupffer cells in control sections of normal liver (Fig. 2).

TABLE 1. Grading and Distribution of Immune Cells in Steatohepatitis $1 \mathrm{~N}$

\begin{tabular}{|c|c|c|c|c|c|c|}
\hline \multirow{2}{*}{ Case } & \multirow{2}{*}{ Sex } & \multirow{2}{*}{ Age (y) } & \multirow{2}{*}{ 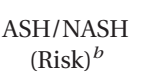 } & \multicolumn{3}{|c|}{ Distribution $^{a}$} \\
\hline & & & & CD3 & CD20 & CD68 \\
\hline 1 & F & 31 & NASH & $2+(V)$ & $\mathrm{R}(\mathrm{V})$ & $\operatorname{Agg}(V)$ \\
\hline & & & $(\mathrm{Ob})$ & $2+(\mathrm{P})$ & & \\
\hline 2 & $\mathrm{M}_{0}$ & 51 & $\begin{array}{l}\text { NASH } \\
\text { (Ob) }\end{array}$ & $\begin{array}{l}1+(\mathrm{V}) \\
1+(\mathrm{P})\end{array}$ & $\mathrm{R}(\mathrm{V})$ & Agg (V) \\
\hline 3 & M & 63 & NASH & $3+(V)$ & $\mathrm{R}(\mathrm{P})$ & $\operatorname{Agg}(V)$ \\
\hline & 2 & 0 & $(\mathrm{Ob})^{a}$ & $3+(\mathrm{P})$ & & \\
\hline 4 & $\mathrm{~F}$ & 55 & NASH & $2+(V)$ & $\mathrm{R}(\mathrm{V})$ & $\operatorname{Agg}(V)$ \\
\hline & & & (Ob) & $1+(\mathrm{P})$ & & \\
\hline 5 & F & 39 & ASH & $\begin{array}{r}1+(\mathrm{V}) \\
\mathrm{R}(\mathrm{P})\end{array}$ & $\mathrm{O}$ & $\operatorname{Agg}(\mathrm{V})$ \\
\hline 6 & M & 51 & $\begin{array}{l}\text { NASH } \\
\text { (D) }\end{array}$ & $\begin{array}{l}1+(\mathrm{V}) \\
2+(\mathrm{P})\end{array}$ & $\mathrm{R}(\mathrm{P})$ & Agg $(V)$ \\
\hline 7 & F & 59 & ASH & $\begin{array}{l}2+(\mathrm{V}) \\
2+(\mathrm{P})\end{array}$ & $\mathrm{R}(\mathrm{V})$ & Agg (V) \\
\hline 8 & $\mathrm{~F}$ & 35 & ASH & $\begin{array}{l}2+(\mathrm{L}) \\
2+(\mathrm{SE})\end{array}$ & $\mathrm{O}$ & $\operatorname{Agg}(V)$ \\
\hline 9 & M & 64 & ASH & $\begin{array}{l}1+(\mathrm{L}) \\
2+(\mathrm{SE})\end{array}$ & $1+(\mathrm{SE})$ & $\operatorname{Agg}(V)$ \\
\hline 10 & $\mathrm{~F}$ & 76 & $\begin{array}{c}\text { NASH } \\
(\mathrm{Ob})\end{array}$ & $\begin{array}{l}2+(\mathrm{V}) \\
1+(\mathrm{P})\end{array}$ & $\mathrm{R}(\mathrm{P}+\mathrm{V})$ & $\operatorname{Agg}(V)$ \\
\hline 11 & M & 71 & ASH & $\begin{array}{l}2+(\mathrm{V}) \\
3+(\mathrm{P})\end{array}$ & $\begin{array}{l}1+(\mathrm{V}) \\
1+(\mathrm{P})\end{array}$ & Agg $(V)$ \\
\hline
\end{tabular}

\footnotetext{
ASH, alcoholic steatohepatitis; NASH, nonalcoholic steatohepatitis.

${ }^{a}$ Lobular distribution of immune cells includes $\mathrm{V}$ (perivenular), $\mathrm{P}$ (portal tract), L (lobular sinusoids), and SE (within fibrous septa). Agg, aggregates.

${ }^{b}$ NASH risk factors include obesity (Ob) and diabetes (D).

${ }^{c}$ Case 3 was also hepatitis $\mathrm{C}$ virus positive.
} 
One case of NASH (Case 4) was sectioned serially and stained alternately with hematoxylin and eosin (H\&E) and CD68 immunostaining to closely compare the routine light-microscopic appearances with the corresponding adjacent immunostain results (Fig. 3A and B). This case showed aggregated and enlarged Kupffer cells in sinusoids directly surrounding hepatocytes with severe hydropic swelling and Mallory bodies. Inspection of the H\&E section disclosed the relative inconspicuousness of the Kupffer cells in these foci as well as the potential for misidentifying them as lymphocytes or endothelial cells. In addition, these sections demonstrated that some of the large lipid vacuoles that appeared to be within hepatocytes on routine $\mathrm{H} \& \mathrm{E}$ were within Kupffer cells (Fig. 3B). This was also found in other $\mathrm{SH}$ cases and in the control fatty livers (see below).

CD68 Immunostaining of Normal and Fatty Liver

The normal liver showed a diffuse sinusoidal distribution of elongated individual Kupffer cells (Fig. 2). This pattern was maintained in the fatty livers (Fig. 4A and B), without the perivenular aggregation seen in cases of SH. Kupffer cells in the fatty livers were occasionally enlarged (Fig. 4B) and rarely contained lipid vacuoles.

\section{DISCUSSION}

Although classic morphologic studies have long emphasized infiltration of neutrophils in the hepatic lesion of alcoholic hepatitis $(8,10)$, more recent investigations of the pathogenesis of $\mathrm{SH}$ in alcoholic and nonalcoholic individuals have demonstrated the presence of a complex cytokine network in which Kupffer cells and lymphocytes play important roles $(5,14)$. Among the cytokines involved in SH, generation of TNF- $\alpha$ and TNF- $\alpha-$ inducible cytokines such as interleukin-1, -6 , and -8 were stressed in a recent overview of the topic by Tilg and Diehl (5). The significance of TNF- $\alpha$ activation of nuclear factor-kappa B in monocytes in alcoholics and the subsequent transcription of inflammation-related genes have also been the subject of recent studies $(15,16)$.

Our study reconfirms earlier work that immunohistochemically demonstrated $\mathrm{T}$ cells in the livers of

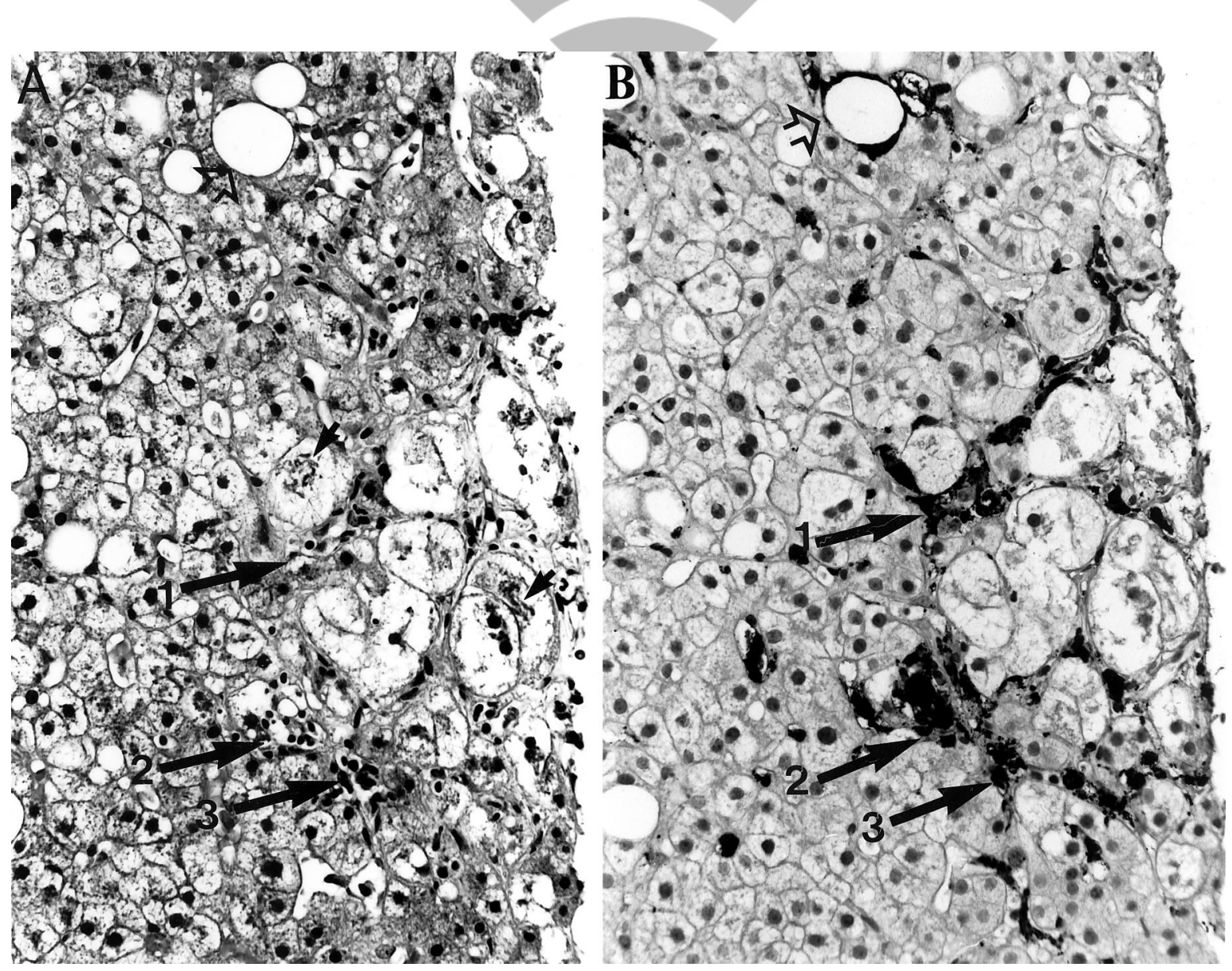

FIGURE 3. A and B are consecutive serial sections from a case of severe NASH. A, the centrilobular region at center right shows markedly ballooned hepatocytes, many of which contain Mallory bodies (short arrows). Sinusoidal inflammation at Points 1, 2, and 3 correspond in B to prominent aggregates of Kupffer cells. A large lipid droplet at top appears to be within a hepatocyte (open arrow). Hematoxylin and eosin stain $325 \times$. B, CD68-immunostained serial section demonstrates Kupffer cells aggregates within sinusoids. A large vacuole of lipid at top is enclosed within a Kupffer cell (open arrow; specific immunoperoxidase; magnification, $325 \times$.) 

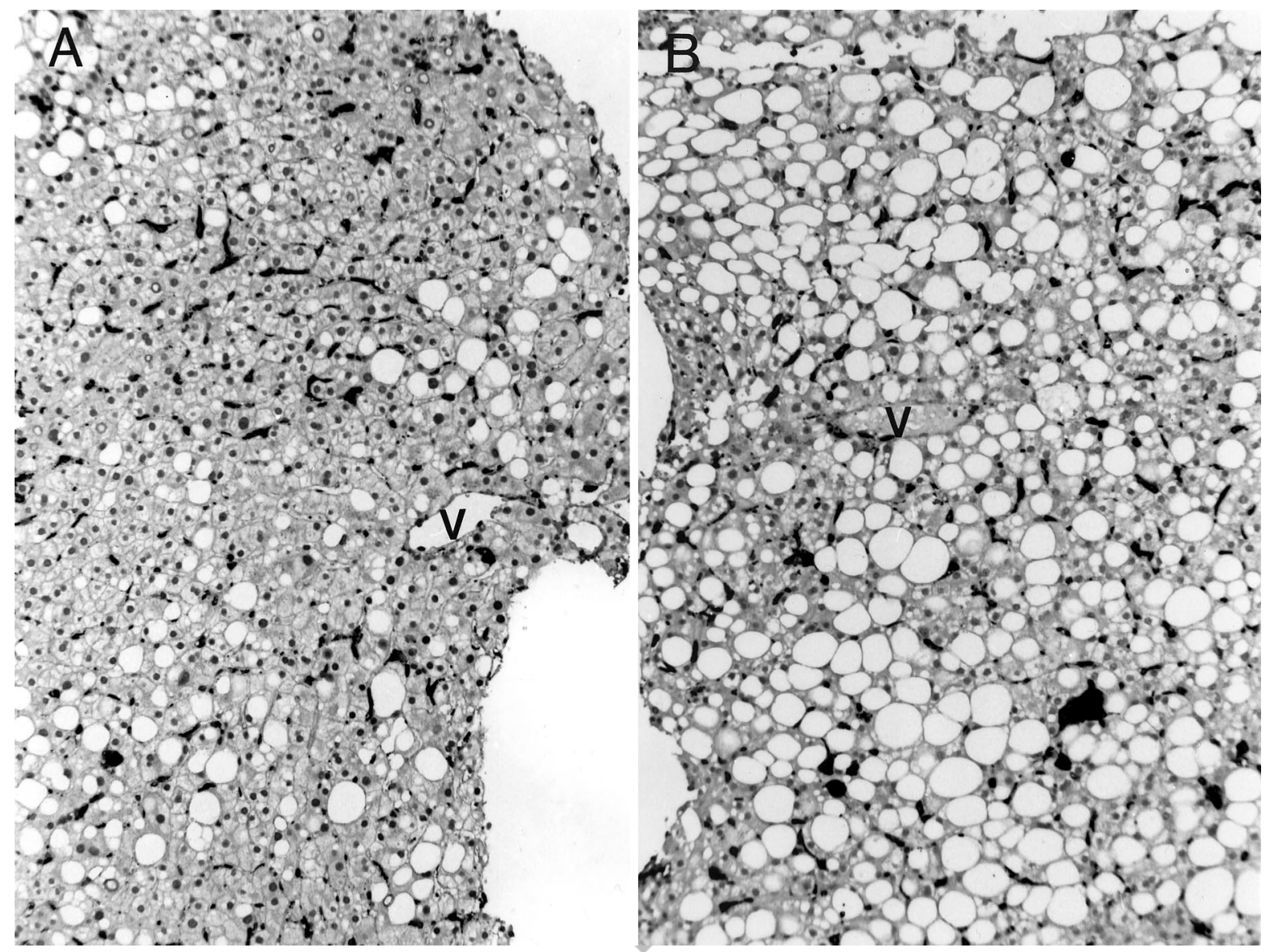

FIGURE 4. Mild (A) and marked (B) fatty liver with CD68 immunostaining for Kupffer cells. A diffuse sinusoidal distribution of individual Kupffer cells is present, without perivenular aggregation. $\mathrm{V}=$ central vein. An enlarged Kupffer cell is seen near the bottom in B. (Magnification, A and B, $125 \times$.)

individuals with alcoholic liver disease (14). A comparative light-microscopic study of ASH and NASH also recorded the presence of $1+$ portal inflammation in 49 and $57 \%$ of cases, respectively (12), whereas another study of NASH found 21 of 49 cases to have predominance of perivenular mononuclear cells (13). In our study, portal tract and sinusoidal $\mathrm{T}$ cells were generally mild to moderate in number. B cells were rarely identified, as also shown in the study of Chedid et al. (14).

The most distinctive finding in our study was the presence of aggregates of enlarged Kupffer cells in perivenular regions of steatohepatitis, as compared with the diffuse, panlobular sinusoidal distribution seen in the normal or fatty liver without SH. On routine light microscopy, these Kupffer cells may be relatively inapparent or mistaken for lymphocytes or endothelial cells. The presence of Kupffer cells among the constituent inflammatory infiltrates of SH was not assessed in several classic pathologic studies of alcoholic hepatitis (8-10) but was cited in a recent ultrastructural and immunohistochemical investigation of stellate and Kupffer cells in 35 patients with alcoholic liver disease (17). The latter study also demonstrated clusters of Kupffer cells with CD68 immunostaining.

The finding of lipid vacuoles in some Kupffer cells suggests that these cells may be processing lipid or phagocytosing effete fatty hepatocytes. Lysosomal activity in these Kupffer cells could represent one mechanism by which reactive oxygen species are generated in the fatty liver.

The localization of Kupffer cells to perivenular regions of steatohepatitis is consonant with the current view that the pathogenesis of this condition is related to intrahepatic release of TNF- $\alpha$ by Kupffer cells, with subsequent generation of cytokines such as interleukin-1, interleukin-6, interleukin-8 and transforming growth factor- $\beta$ (5). Induction of CD14 receptors on Kupffer cells by ethanol or by lipopolysaccharide of endotoxin appears to be a critical event preceding the cytokine cascade and production of reactive oxygen species by Kupffer cells $(6,7)$. Future immunohistochemical studies to evaluate expression of CD14 receptors on Kupffer cells in SH would provide additional support for this concept.

In summary, this study demonstrated the presence of $\mathrm{T}$ cells and Kupffer cells as constituents of 
the inflammatory lesion of ASH and NASH, with unusual prominence of enlarged and aggregated Kupffer cells present in perivenular regions of steatohepatitis. No significant differences between steatohepatitis of alcoholic versus nonalcoholic type were detected in the numbers or distribution of these inflammatory cells. Although previous histopathological criteria for the diagnosis of steatohepatitis have stressed the presence of neutrophil infiltrates, a contemporary comprehensive morphologic definition of this lesion should provide a more inclusive approach to the spectrum of inflammation seen, with particular recognition of the participation of Kupffer cells.

Acknowledgments: The authors thank Dianne Alexis and Ritchie Alsberry for immunohistochemical staining and Alfred Lamme for photography.
6. Järveläinen HA, Fang C, Ingelman-Sundberg M, Lindros KO. Effect of chronic coadministration of endotoxin and ethanol on rat liver pathology and proinflammatory and antiinflammatory cytokines. Hepatology 1999;29:1503-10.

7. Järveläinen HA, Fang C, Ingelman-Sundberg M, Lukkari TA, Sippel H, Lindros KO. Kupffer cell inactivation alleviates ethanol-induced steatosis and CYP2E1 induction but not inflammatory responses in rat liver. J Hepatol 2000;32:90010

8. Mallory FB. Cirrhosis of the liver. Five different types of lesions from which it may arise. Bull Johns Hopkins Hosp 1911;22:69-74

9. French SW, Nash J, Shitabata P, et al. Pathology of alcoholic liver disease. Semin Liver Dis 1993;13:154-69.

10. Baptista A, Bianchi L, De Groote J, et al. Alcoholic liver disease: morphological manifestations. Lancet 1981;1:707-11.

11. Ludwig J, Viggiano TR, McGill DB, Oh BJ. Nonalcoholic steatohepatitis: Mayo Clinic experiences with a hitherto unnamed disease. Mayo Clin Proc 1980;55:434-8.

12. Diehl AM, Goodman Z, Ishak KG. Alcohollike liver disease in nonalcoholics. A clinical and histologic comparison with alcohol-induced liver injury. Gastroenterology 1988;95:105662.

13. Lee RG. Nonalcoholic steatohepatitis: a study of 49 patients. Hum Pathol 1989;20:594-8.

14. Chedid A, Mendenhall CL, Moritz TE, et al. Cell-mediated hepatic injury in alcoholic liver disease. Gastroenterology 1993;105:254-66.

15. Szabo G. New insights into the molecular mechanisms of alcoholic hepatitis: a potential role for NF-KB activation? J Lab Clin Med 2000;135:367-9.

16. Hill DB, Barve S, Joshi-Barve S, McClain C. Increased monocyte nuclear factor-KB activation and tumor necrosis factor production in alcoholic hepatitis. J Lab Clin Med 2000;135: 387-95.

17. Cameron RG, Neuman MG. Novel morphologic findings in alcoholic liver disease. Clin Biochem 1999;32:579-84.

5. Tilg H, Diehl AM. Cytokines in alcoholic and nonalcoholic steatohepatitis. N Engl J Med 2000;343:1467-76. 